\title{
AS RELAÇÕES DE GÊNERO E SUAS INTERFACES COM O PROGRAMA SABERES DA TERRA NA ESCOLA CORRE-MÃO MUNICÍPIO DE IGARAPÉ-MIRI/PA
}

\author{
Paulo Emil Rodrigues CHAVES ${ }^{1}$ \\ Secretaria Municipal de Educação de Moju \\ Lucielma Lobato SILVA ${ }^{2}$ \\ Secretaria de Educação do Estado-SEDUC
}

Resumo: Este trabalho trata das relações de gênero e suas interfaces com o programa Saberes da terra, fundamentado nos conceitos e princípios da educação do campo, fruto das lutas dos movimentos sociais, que tem como método a pedagogia da alternância. A pesquisa de cunho qualitativo foi desenvolvida na Escola Corre-Mão, município de Igarapé-Miri-Pá. A metodologia utilizada corresponde à pesquisa bibliográfica e à realização de entrevistas semiestruturadas com alunas, professores do programa, a fim de termos um recorte de como tais relações se constroem no ambiente escolar e familiar. Tais entrevistas mostraram que, na escola, são reproduzidas as mesmas relações de submissão e preconceito, sobre as quais, ao longo do tempo, as mulheres são submetidas.

Palavras-Chave: Educação do campo. Saberes da terra. Relações de gênero.

\begin{abstract}
This work deals with gender relations and its interfaces with the land knowledge program, based on the concepts and principles of rural education, the fruit of the struggles of social movements, whose method is the pedagogy of alternation. The qualitative research was developed, in the School Run-By the municipality of IgarapéMiri / Pa. The methodology used was a bibliographical research and the realization of semi-structured interviews with students, teachers of the program, to have a clipping of how such relationships are built in the school and family environment. These interviews showed that at school the same relations of submission and prejudice are reproduced, that over time women are submitted.
\end{abstract}

Key-Words: Field education. Land knowledge. Gender relations.

\footnotetext{
${ }^{1}$ Possui graduação em Educação do Campo pela Universidade Federal do Pará (2016). Tem experiência na área de Matemática, com ênfase em Matemática. Especialização em Educação do Campo e Extensão Rural. E-mail: pauloemiles@yahoo.com.br.

2 Doutora em Antropologia, mestre em Ciências da Religião, Historiadora. E-mail: lucielma.lobato@gmail.com.
} 


\section{Introdução}

A educação do campo é um tema recente no bojo das políticas públicas de educação no Brasil, fruto das lutas dos movimentos sociais e pautada pela Lei de Diretrizes e Bases - LDB 9.394/96. Segundo esta, é necessário que os conteúdos curriculares e metodologias estejam adaptados às reais necessidades e aos interesses dos alunos do campo, que haja uma organização escolar própria, adequando o calendário escolar aos ciclos agrícolas e às condições climáticas locais, priorizando a formação voltada para a sustentabilidade do campo. Como destaca Caldart (2004), a população tem o direito de ser educada no lugar onde vive, defende o direito a uma educação pensada desde o lugar e com sua participação, vinculada a sua cultura e as suas necessidades humanas e sociais.

O presente artigo tem como objetivo analisar as relações de gênero e suas interfaces com o programa Saberes da terra, na escola Corre-Mão, município de IgarapéMiri-Pá. A escola Corre-Mão, lócus do trabalho, está localizada à margem esquerda do Rio Itamimbuca, localizado na divisão dos municípios de Igarapé-Miri e Abaetetuba, situado na Mesorregião do Nordeste Paraense, que compreende parte do território da microrregião do Baixo Tocantins ${ }^{3}$.

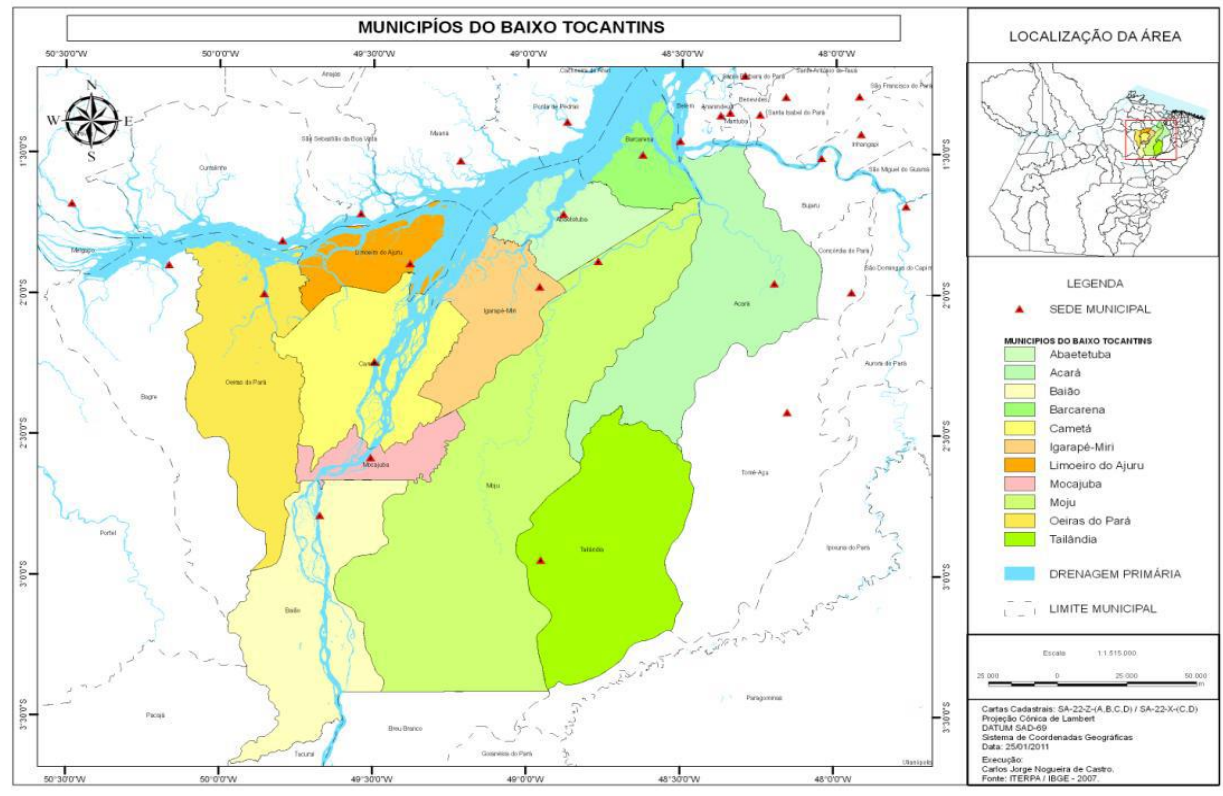

Fonte: ITERPA/IBGE-2007

\footnotetext{
${ }^{3}$ Abaetetuba, Acará, Baião, Barcarena, Cametá, Limoeiro do Ajurú, Mocajuba, Mojú, Oeiras do Pará e Tailândia. 
O Rio Itamimbuca, pela margem direita, faz parte do município de Abaetetuba, e os moradores são do assentamento agroextrativista da Ilha Piquiarana; pela margem esquerda, faz parte do município de Igarapé-Miri, por isso seus moradores são do assentamento agroextrativista da Ilha Mutirão/Japurete, e do assentamento Emanuel. A economia da comunidade é baseada na agricultura familiar ${ }^{4}$.

Este trabalho está organizado em quatro tópicos: i. Foi construído a partir da fundamentação teórica sobre a pedagogia da alternância e educação do campo, evidenciando princípios e conceitos que, ao longo do tempo, foram construídos e que são frutos das lutas dos movimentos sociais, culminando na disseminação de experiências, as quais possibilitaram um novo olhar sobre a educação do campo, com uma organização voltada para a sua realidade e suas especificidades; ii. Relata a trajetória do programa Saberes da terra, na escola Corre-Mão, município de Igarapé-Miri; iii. Faz referência à entrevista realizada com o coordenador do programa Saberes da terra, que relata como as políticas de educação do campo estão sendo desenvolvidas naquele território desde o ano de 2005 até os dias atuais; iv. Trata de como tem se construído as relações de gênero no programa Saberes da terra, na escola Corre-Mão - neste tópico, estão concentradas as transcrições das entrevistas realizadas com alguns sujeitos da mencionada escola; nas entrevistas não citamos nomes, para preservar a identidades dos(a) entrevistados(a), conforme a solicitação deles.

Faremos uma abordagem do termo gênero com referência às relações sociais desiguais de poder entre homens e mulheres que são o resultado de uma construção social, historicamente construída, do papel do homem e da mulher, a partir de suas diferenças sexuais. $\mathrm{O}$ que gera o entendimento de que as atividades desenvolvidas pelas mulheres no meio rural, na maioria das vezes, são simplesmente uma ajuda, fazendo menção com a Pedagogia da Alternância, pela ótica da divisão do trabalho, levando em consideração que essa escola tem como ação educativa a Pedagogia da Alternância, que é uma concepção de ensino com uma metodologia que alterna períodos na escola e na família, denominados de tempo-escola e tempo-comunidade. "É a vinculação entre o meio escolar e o meio familiar-comunitário". Esse sistema deve permitir aos jovens frequentar à escola sem prejudicar ou inviabilizar a produção realizada através de laços e braços da família" (RIBEIRO, 2003, p. 142).

\footnotetext{
${ }^{4}$ Agricultura familiar é entendida como uma forma social de trabalho e produção que ainda conserva traços típicos do campesinato (WANDERLEY apud HERNADÉZ, 2009), isto é, a base social da produção é a familiar.
} 
A Pedagogia da Alternância e a Educação do Campo na Perspectiva dos Saberes da Terra em Igarapé-Miri

A Pedagogia da Alternância tem como premissa a formação integral e transformadora do meio, conciliando os diversos saberes e espaços (conhecimentos tradicionais e científicos, família e escola), em um processo dialógico, fundamentado nos princípios da ação-reflexão-ação das vivências dos sujeitos que fazem sua vida no e com o campo. Nas palavras de Gemonet (apud Vergutz e Cavalcante, 2014):

O processo de criação da Pedagogia da Alternância esteve coerente com o seu objetivo. Os agricultores inventores e seus porta-vozes pedagógicos não se basearam em teorias ou conceitos para coloca-los em prática de maneira dedutiva. Não, eles perceberam, escutaram e se conscientizaram dos problemas, das necessidades. Questionaram-se, formularam hipóteses e têm enunciado soluções... Em seguida, inventaram, realizaram, agiram, implementaram, arriscaram. Uma vez engajada a ação, observaram, escutaram, olharam as práticas. Analisaram, destacaram os componentes do sistema e os fatores de êxito e de fracasso... Disto tudo extraíram ideias, pensamentos, saberes e conhecimentos, mesmo que fossem empíricos. Confrontaram com outros, diferentes, para atingir outros saberes, outros conhecimentos mais amplos no campo das ciências educativas... para entender melhor, agir melhor a fim de prestar um serviço educativo, responder às necessidades, contribuir para 0 desenvolvimento das pessoas e do meio rural (2007, p.27).

Teve sua origem na década de 1930, na França, como uma forma de adequação da educação ao modo de vida da população rural, alienada dos seus direitos por parte do Estado, intercalando tempo escola e o tempo comunidade. Segundo explicita Vergutz e Cavalcante (2014), no Brasil, a primeira experiência com Pedagogia da Alternância foi com a implantação de uma Escola Família Agrícola (EFA), no estado do Espírito Santo, em 1968, em Olivânia, no município de Anchieta, a partir da experiência trazida pelo religioso Jesuíta Padre Umberto Pietrogrande. Em meados da década de 1970, houve a expansão para outros estados brasileiros, por meio de diferentes intercâmbios que almejavam, com um trabalho de base, disseminar a Pedagogia da Alternância para e com sujeitos do campo.

Esta pedagogia vai além de uma metodologia, ela fundamenta-se num diálogo problematizador para além de "um pensar ingênuo em busca de um pensar crítico" (FREIRE, 1987, apud VERGUTZ \& CAVALCANTE, 2014). Ressalta ainda que nessa 
perspectiva o educador tem de "saber que ensinar não é transferir conhecimento, mas criar possibilidade para sua própria produção ou a sua construção" (FREIRE, 1996, p. 47). Sendo assim, o papel do educador é o de preparar o jovem para a vida em sociedade, fazendo-o refletir acerca do seu meio, da família, da comunidade, despertando nele um sentimento de pertença e empoderamento de sua existência e identidade, conforme explicita o depoimento de um monitor do programa Saberes da terra, do município de Igarapé-Miri-Pá:

Nós trabalhamos com a metodologia da pedagogia da alternância, onde o aluno fica uma semana na escola e a outra no lote da família desenvolvendo as atividades práticas, atividades agrícolas, como de produção de horta, criação de peixe, manejo de açaizal, e outras atividades, né, em fim a gente trabalha com aquilo que é a realidade da comunidade, objetivo não é só ensinar a ler e escrever, mais contribuir para que o aluno possa melhorar sua produção, melhorar a vida da comunidade, que ele possa se sentir como alguém que pode contribuir com o desenvolvimento do seu lugar, que o campo seja visto como lugar de perspectivas, de felicidade, fazendo ele entender que pra ser feliz não é preciso sair do campo (monitor do programa Saberes da terra).

Partilhamos das reflexões de Fernandes (2009, p.131) e Caldart (2004) que olham para o campo como um lugar de vida, onde as pessoas podem morar, trabalhar, estudar com dignidade de quem tem o seu lugar, a sua identidade cultural. A população do campo tem o direito de ser educada no lugar onde vive, com uma educação pensada desde o seu lugar e com a sua participação, vinculada a sua cultura e as suas necessidades humanas e sociais, desconstruindo a imagem historicamente criada de que o campo é lugar de atraso. Para Arroyo (2006), “... a imagem que temos na academia, na política, nos governos é que para a escolinha rural qualquer coisa serve. Para mexer enxada não há necessidade de letras". As denúncias podem ser observadas no relatório da I Conferência Nacional Por Uma Educação Básica do Campo, que ocorreu de 27 a 31 de Julho de 1998, em Luziânia- GO:

Faltam escolas para atender a todas as crianças e jovens; ainda há muitos adolescentes e jovens fora da escola; Falta infraestrutura nas escolas e ainda há muitos docentes sem formação necessária; Falta uma política de valorização do magistério; Falta apoio às iniciativas de renovação pedagógica; Falta financiamento diferenciado para dar conta de tantas faltas; Os mais altos índices de analfabetismo estão no campo; Currículos são deslocados das necessidades e das questões do campo e dos interesses dos seus sujeitos (I CONFERENCIA NACIONAL POR UMA EDUCAÇÃO BÁSICA DO CAMPO, p. 10). 
É nesse contexto que nasce o movimento por uma educação do campo, com a participação dos movimentos sociais ${ }^{5}$, de luta por uma educação pensada para o campo, que leve em consideração as suas especificidades, diversidades, identidades, culturas, desenvolvimento sustentável e solidário, entendo que essa educação deve ser garantida pelo Estado, pois, segundo a LDB 9.394/96, é necessário que os conteúdos curriculares e metodologias estejam adaptados às reais necessidades e aos interesses dos alunos do campo, que haja uma organização escolar própria, adequando o calendário escolar aos ciclos agrícolas e às condições climáticas locais, priorizando a formação voltada para a sustentabilidade do campo, ainda segundo as Diretrizes Operacionais para a Educação Básica nas Escolas do Campo. A identidade da escola do campo é definida da seguinte maneira:

Art. 2 - Parágrafo único. A identidade da escola do campo é definida pela sua vinculação às questões inerentes à sua realidade ancorando-se na temporalidade e saberes próprios dos estudantes, na memória coletiva que sinaliza futuros, na rede de ciência e tecnologia disponível na sociedade e nos movimentos sociais em defesa de projetos que associem as soluções exigidas por essas questões à qualidade social da vida coletiva do País. (BRASIL, 2002, p.37).

Essa organização potencializou a realização da II Conferência de Educação do Campo em 2004, com a participação dos sujeitos do campo, profissionais da educação e representantes do governo, na qual foram pautadas as políticas de educação do campo.

Um dos traços fundamentais que vem desenhando a identidade deste movimento por uma educação do campo é a luta do povo do campo por políticas públicas que garantam o seu direito à educação e a uma educação que seja no e do campo. No: o povo tem direito a ser educado no lugar onde vive; Do: o povo tem direito a uma educação pensada desde o seu lugar e com a sua participação, vinculada a sua cultura e as suas necessidades humanas e sociais (CALDART, 2004, p.149).

\section{O programa Projovem campo saberes da terra no município de Igarapé-Miri}

Para entendermos a trajetória do programa Saberes da terra, no município de Igarapé-Miri realizamos entrevista em dois momentos. No primeiro momento, foi realizada uma visita à Secretaria Municipal de Educação, especificamente no

\footnotetext{
${ }^{5}$ Movimento dos Trabalhadores Sem Terra, Movimento dos Pequenos Agricultores, Escolas Famílias Agrícolas, Movimento das Mulheres Trabalhadoras Rurais, Movimento dos Atingidos por Barragens, Movimento dos Indígenas, Movimento de Organização Comunitária, Pastoral da Juventude Rural, Comissão Pastoral da Terra, Conselho Indigenista Missionário, Comunidades Quilombolas etc. 
departamento de educação do campo, onde o coordenador do programa Saberes da terra e ProJovem Campo, professor Armando Cleydson Farias Pantoja ${ }^{6}$, fez um relato da trajetória do programa no município de Igarapé-Miri, conforme transcrito abaixo:

"As primeiras experiências com a pedagogia da alternância surgiram no município em 2005 com a experiência da Casa Familiar Rural (CFR), localizada no rio Meruu-Açu (associação Multirão ponta negra), e que em 2006 mudou a nome para saberes da terra, devido várias ações da sociedade e do Estado brasileiro no ano de 2005 o Ministério da Educação por meio da Secretaria de Educação Continuada, Alfabetização e Diversidade (SECAD/MEC) que integra a Coordenação Nacional de Educação do Campo criou a Primeira versão do Programa Saberes da Terra que foi implementada em vários Estados do Brasil. Destinado a fazer formação em nível de Ensino Fundamental integrada com Qualificação Social e Profissional de jovens agricultores na faixa etária de 15 a 29 anos que vivem e trabalham no campo. Atualmente o Programa encontra-se na sua segunda versão (2008 -2010) e denomina- se Projovem CampoSaberes da Terra e atende jovens de 18 a 29 anos que não concluíram o ensino fundamental".

Segundo ele, no estado do Pará, a segunda versão do ProJovem Campo e Saberes da Terra vem sendo coordenada pela Secretaria de Estado de Educação/SEDUC, por meio da Coordenação de Educação do Campo, das Águas e das Florestas/CECAF, responsável pela gestão administrativa e pedagógica e pelo Instituto de Educação, Ciência e Tecnologia do Pará - IFPA, que é a Instituição de Ensino Superior responsável em promover a formação continuada ao nível de especialização (para os que já possuem a graduação) e aperfeiçoamento (para os que possuem ensino médio) aos educadores que atuam diretamente com os alunos em sala de aula. O programa conta também com a parceria de diversas instituições que fazem parte do Fórum Paraense de Educação do Campo. Hoje pode ser considerada uma política pública da secretaria, "é o grito da educação do campo dentro da secretaria de educação do município voltada a atender os sujeitos do campo respeitando a suas diversidades".

Sobre a demanda atendida pelo programa no município e a metodologia utilizada, o coordenador do programa disse que:

No município de igarapé-Miri são atendidas atualmente cinco comunidades com o programa saberes da terra, (comunidades; São João do rio Meruu, Pindobal, Paraíso Rio Meruu, Furo-seco Rio Meruu e Corre Mão rio Itamimbuca), o programa contempla

\footnotetext{
${ }^{6}$ Licenciado pleno em Matemática, especialista em Matemática, cursando graduação em Gestão Escolar, coordenador municipal do programa "Saberes da terra".
} 
100 alunos que participam ativamente. A metodologia de o Programa Saberes da Terra é no modelo de alternância que consiste em processo educativo no qual o aluno alterna períodos de aprendizagem na família com períodos na escola. Nessa sistemática o tempo escolar e o tempo comunidade são interligados por meio de instrumentos pedagógicos específicos capazes de construir uma harmonia entre as comunidades e a ação pedagógica. No tempo escola o aluno estuda em tempo integral. Já o tempo comunidade é destinado a estudos e pesquisas da realidade local que devem servir como base para o processo pedagógico no período de tempo escola.

A certificação é feita via IFPA de Abaetetuba, a partir de um acordo de pactuação para que o certificado seja expedido por uma instituição de ensino federal. Além da base curricular comum, os currículos contêm ênfase em agricultura familiar. Segundo o coordenador do programa, três turmas estão em fase de conclusão, mas já existem novas demandas no município as quais ele espera ter condições de contemplar em novas turmas. Ainda segundo o coordenador do programa, o seu Projeto Político Pedagógico (PPP) está sendo construído com a participação dos movimentos sociais locais, Sindicato dos Trabalhadores Rurais (STTR), Sindicato dos Trabalhadores na Educação (SIMTEP), entre outros.

No segundo momento, foi realizada visita na Escola Municipal de Ensino Fundamental Corre-Mão, esta localizada no Rio Itamimbuca, Município de Igarapé-MiriPá, fundada em 1988. Atende alunos das séries iniciais do ensino fundamental e, no ano 2017, foi contemplada com o programa Saberes da Terra, fato determinante para tomarmos esta unidade de ensino como lócus do presente trabalho. Segundo a diretora da escola, professora Denise Afonso ${ }^{7}, 35$ alunos estão matriculados no programa, mas apenas 26 frequentam ativamente; para ela, o programa é uma novidade, encantadora pela metodologia da alternância pedagógica, na qual os alunos têm o tempo escolar e o tempo da comunidade, com isso eles podem trabalhar e estudar, reduzindo assim a evasão escolar.

Além disso, segundo a professora Denise, o programa é interessante por se adequar à diversidade produtiva da comunidade. Nesse sentido, ela explica que no tempo escolar os alunos aprendem, além das disciplinas da base curricular comum (português, matemática, história etc.), a cultivar os sistemas produtivos locais, isso faz com que no tempo comunidade eles coloquem em prática o que aprenderam na escola, melhorando

\footnotetext{
${ }^{7}$ Licenciada em pedagogia, coordenadora da escola corre mão. MARGENS - Revista Interdisciplinar 
assim a produção na comunidade. O programa conta com uma infraestrutura boa, um excelente quadro de professores, barqueiros e outros servidores. Atende alunos das comunidades Itamimbuca, ilha do Uruá e São bento. A diretora se diz satisfeita com o programa e espera que a escola colha bons frutos dele.

\section{As relações de gênero no programa Saberes da Terra na escola Corre-Mão}

A luta das mulheres por emancipação ganhou força a partir da década de 1960, conforme ressaltam Pedro (2005) e Andrade (2007). Os autores reforçam essa afirmação ao explicar que estes termos surgem como forma de expor uma relação de poder e conflito social que, ao longo do tempo, tem intensificado as desigualdades dos indicadores de desenvolvimento e qualidade de vida das mulheres em relação aos homens.

Para Miranda e Schimanski (2014, p. 68),

Analisar as questões de gênero hoje, nos remete à busca de informações na História, na antropologia, na Sociologia e na Filosofa, entre outras disciplinas, para que possamos compreender como o processo das relações entre os seres humanos vem sendo construído, desde as sociedades mais antigas até nossa época. Isso nos leva a compreender que a concepção de gênero passa por um domínio que tem caráter interdisciplinar. Nesse sentido, o conceito de gênero está envolto por diferentes significados e articulado a categorias sociais abrangentes, como, por exemplo, a desigualdade social.

Discutir as relações de gênero é trazer à tona toda uma história de opressão dos homens em relação às mulheres, historicamente construída por uma sociedade de classes que define os papéis. Segundo Faria e Nobre (2015), a construção social das desigualdades de gênero é gerada pela sociedade e não determinada pela diferença biológica entre os sexos. As desigualdades são uma construção social, não determinadas pelo sexo.

Faremos um relato de algumas entrevistas que realizamos junto de alunas(os), professores do programa Saberes da terra, na escola Corre-Mão, para analisarmos como vem se construindo as relações de gênero dentro do estabelecimento de ensino e concluiremos com fundamentação teórica do assunto.

Analisar as relações de gênero dentro do programa Saberes da terra, no município de Igarapé-Miri, especificamente na escola Corre-mão, é entrar em um universo particular de significados e ações, que são construídos pelos que lá vivem (monitores, coordenadores pedagógicos, cozinheiras, alunos, alunas etc.). Entretanto, esse é um espaço com reflexos sociais e culturais que são trazidos através das experiências dos 
indivíduos em seus diversos contextos como familiares, comunitários ${ }^{8}$ e organizações dos movimentos sociais, ou seja, de cada lugar se trazem múltiplas experiências que, durante duas semanas de cada mês, são socializadas através de momentos em sala de aula e em atividades de campo.

As informações do autor são ratificadas pela Informante $\mathrm{A}^{9}$ :

"Nas aulas de campo, quando as mulheres realizam atividades iguais as dos homens, com as mesmas ferramentas, terçado, enxada etc. eles ficam falando que lugar de mulher é na cozinha, que nós somos muito devagar pra fazer as coisas, cria um clima de disputa, eles se acham melhores do que nós, tem momento que eles querem mandar na gente" (Informante A).

As entrevistadas, em sua maioria, afirmam que as relações entre homens e mulheres dentro do programa Saberes da terra são desiguais, pois consideram que há vantagens para os alunos que chegam à escola, ao trazerem consigo todo um aprendizado familiar que referenda o papel secundário do sexo feminino, o que faz com que eles reproduzam essa desigualdade no convívio escolar, elegendo os seus instrumentos de trabalho considerados "masculinos".

"Nas aulas práticas, cabem aos homens, construir os canteiros, carregar a terra, o trabalho, mas pesado é deles nós só ajudamos, cabe a nós, semear as sementes, molhar os canteiros, o trabalho considerado mais leve, e na hora das refeições eles querem que a gente lave a vasilha deles" (Informante B).

É notório que quando alunos chegam à escola, já sabem o papel que corresponde aos sexos relacionados, desde a sua socialização primária no seio da família. Para Cabral e Diaz (1998):

O papel do homem e da mulher é constituído culturalmente e muda conforme a sociedade e o tempo. Esse papel começa a ser construído desde que o (a) bebê está na barriga da mãe, quando a família de acordo à expectativa começa a preparar o enxoval de acordo ao sexo. Dessa forma, cor de rosa para as meninas e azul para os meninos. Depois que nasce um bebê, a primeira coisa que se identifica é o sexo: "menina ou menino" e a partir desse momento começará a receber mensagens sobre o que a sociedade espera desta menina ou menino. Ou seja, por ter genitais femininos ou masculinos, eles são ensinados pelo pai, mãe,

\footnotetext{
${ }^{8}$ São as experiências nas localidades relacionadas com a igreja católica e evangélica.

${ }^{9}$ Optamos por denomina-los assim, a fim de preservar suas identidades, uma vez que os informantes não autorizaram a utilização de seus respectivos nomes.
} 
família, escola, mídia, sociedade em geral, diferentes modos de pensar, de sentir, de atuar.

Dentro do programa Saberes da terra, mulheres e homens atuam a partir das suas perspectivas associadas à formação familiar e, consequentemente, constroem símbolos e significados culturais aos seus comportamentos. Segundo as alunas, estas ainda escutam com frequência, mesmo que nas brincadeiras, frases do tipo "lugar de mulher é na cozinha", expressão que evidencia situações de opressão, preconceito, submissão das relações entre homens e mulheres dentro do contexto escolar.

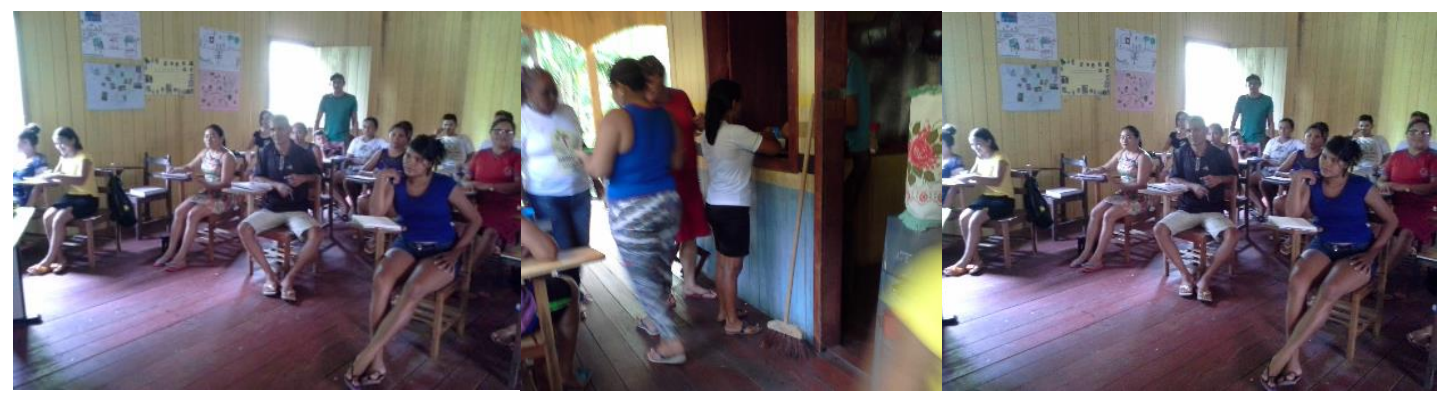

Fonte: Chaves, Paulo Emil Rodrigues; visita de campo, acervo do autor. As imagens mostram os alunos em atividade.

Por outro lado, no decorrer das entrevistas, algumas alunas relataram que desenvolvem atividades em pé de igualdade com os homens. Segundo Cabral e Dias (1998), a situação nos últimos tempos tem mudado e cada vez mais um número maior de mulheres está saindo do lar e está ingressando no mercado de trabalho, no entanto, as desigualdades ainda permanecem. Diferentes estudos mostram que, em geral, as mulheres ganham menos que os homens em todos os campos e que as mulheres têm menos possibilidades de obter um cargo diretivo. Se olharmos essa relação no campo, por mais que as mulheres estejam presentes em todas as etapas do processo produtivo, seu trabalho é pouco valorizado e considerado como uma ajuda.

"Lá em casa, eu e minha irmã ajudamos em quase todos os trabalhos, até pra roça a gente vai, a gente capina, arranca mandioca, faz farinha; na coleta do açaí a gente ajuda, apanha o açaí a disbulhar, temos de ajudar né, sempre foi assim, nós não recebemos ne diária, é um trabalho familiar, temos de ajudar né" (Informante C).

Assim foi se construindo historicamente uma cultura machista que, paulatinamente, invisibiliza a mulher, cabendo a ela apenas ser mãe e cuidar das atividades da casa, conforme pode ser observado na transcrição abaixo.

"Eu moro na ilha, na safra do açaí, eu trabalho na coleta, desbulho açaí para os meus irmãos e eles me pagam, se eles ganham $\mathrm{R} \$$ 
10,00 , eles me dão $\mathrm{R} \$ 2,00$, quando agente chega do mato ainda tem de ir para a cozinha fazer a comida, para eles eu só ajudo, meu trabalho não é o principal, além disso, tem dia que eu coloco Mapati, enfim, ajudo em vários trabalhos, até quando vamos fazer a limpeza do mato do açaizal eu ajudo" (Informante D).

Vale ressaltar que os estudos de gênero são úteis para explicar muitos comportamentos de mulheres e homens em nossa sociedade, nos ajudando a compreender parte dos problemas e dificuldades que as mulheres enfrentam na vida pública, na sexualidade, na reprodução da família e nas relações escolares, como podemos notar no depoimento abaixo, muitas mulheres têm seus direitos negados.

"Quando eu era mais jovem, meu pai não deixou eu continuar
meus estudos, porque não tinha escola próximo de casa pra mim
concluir o ensino fundamental, ele dizia que se eu fosse estudar
pra longe da família eu ia engravidar e por isso tive de parar,
somente depois de 10 anos, hoje já casada pude retornar meus
estudos no programa saberes da terra aqui na escola né,
estudamos eu e meu marido, agente estuda uma semana e na outra
agente pode trabalhar no nosso terreno, assim é melhor, tenho fé
em deus que vou concluir o fundamental pelo menos"
(Informante E).

O depoimento acima evidencia a realidade vivenciada por muitas mulheres no meio rural que tiveram de interromper os estudos por não poderem sair do seio familiar, vítimas de um sistema que trata a mulher como propriedade do homem. Mostra também que o programa Saberes da terra oportunizou a essas mulheres a possibilidade de retornarem aos estudos e seus sonhos.

"Pra mim o saberes da terra foi uma ótima oportunidade né, por que fazia quatro anos que tinha parado de estudar, e agora com o programa funcionando perto de casa, eu pude voltar a estudar, foi muito bom, pra mim e meus colegas, é bom porque da pra estudar e trabalhar ao mesmo tempo, tudo o que a gente aprende aqui, a gente pode fazer lá na nossa casa, eu já construir até horta lá em casa, eu quero que continue né” (Informante F).

Para os(a) alunos(a), o programa Saberes da terra se adequou à realidade da comunidade, pois, a Pedagogia da Alternância possibilita a conciliação entre trabalho e estudo. A perspectiva da educação em alternância oportuniza ao mesmo tempo o jovem estudar e ajudar a família em suas atividades produtivas. Para Azevedo (1999), normalmente quando o jovem sai do campo para frequentar escolas de tempo integral, ele vai perdendo gradativamente o vínculo com a família. Diante dos distanciamentos causados entre a escola e o local de moradia dos alunos, uma das pretensões centrais da 
Pedagogia da Alternância são as relações estabelecidas entre a situação sócio-profissional e a escolar, ou seja, é a associação entre teoria e prática, ação e reflexão, "É uma maneira de aprender pela vida, partindo da própria vida cotidiana, dos momentos de experiências, colocando assim a experiência antes do conceito" (GIMONET, 1999, p. 44).

"Aqui na escola nós trabalhamos com temas geradores, cada semana trabalhamos um tema de maneira interdisciplinar, no tempo escola que estamos aqui na escola, estudamos a parte teórica e nas alternâncias os alunos realizam atividade práticas, quando retornamos da alternância fazemos a socialização das vivências, realizamos visitas nas unidades de produção dos alunos, temos alunos que já tem horta, criação de peixe de frango, penso que estamos contribuindo com o desenvolvimento da comunidade, o programa saberes da terra na sua matriz curricular polonizar essa adaptação às realidades dos alunos, pra mim é gratificante fazer parte disso" (Informante G).

Na alternância, o desenvolvimento do currículo escolar se dá através dos temas geradores definidos com a participação dos professores, dos alunos e de seus familiares. Esse instrumento do "diálogo" resulta na construção dos temas que se iniciam na investigação da realidade e a ela retorna na busca de superação dos problemas encontrados. "Procurar um tema gerador é procurar o pensamento do homem sobre a realidade e sua ação sobre essa realidade que está em sua práxis" (FREIRE, 2000, p.32). Para Hage (apud FERNANDES \& BASTIANI, 2011, p.63):

O currículo constitui-se num espaço de produção e disseminação de conhecimentos, de práticas e políticas culturais. O currículo interfere na produção do imaginário da população, a partir dos valores, comportamentos, atitudes, normas, padrões culturais que veicula, conferindo legitimidade ao projeto social dos grupos que apresentam maior poder na sociedade, atribuindo-lhe um caráter oficial, envolvendo inclusive o apoio dos setores populares.

É dentro desse espaço diverso que é a escola, em particular, o programa Saberes da terra, que as relações de gênero vão se construindo a cada dia, pois, conforme aponta Pedro (2005), são frutos das relações sociais que discutem os papéis de homens e mulheres na sociedade ao longo do tempo, tais transformações dos papéis sociais de homens e mulheres começaram a acontecer no século XVIII, em virtude de importantes mudanças políticas, sociais, culturais e econômicas, tais como: a ascensão da burguesia, criação dos Estados nacionais, início da industrialização e a formação da sociedade capitalista. 
Nesta nova família, aparece a figura da criança como aquele membro que precisa de cuidados especiais para desenvolver-se bem, afinal, ela é o futuro dos Estados nacionais em construção. Para atender a essa nova exigência social, a mulher foi confinada na esfera doméstica, onde, por amor, passou a viver com o objetivo de cuidar dos(as) filhos(as), marido e casa. Começa, então, a ser institucionalizada a característica "cuidadora" da mulher, refletida nas suas atuações como mãe, esposa e dona-de-casa (ROCHA-COUTINHO, 1994).

A mulher passa a viver para o amor: amor a seus filhos, a seu esposo, a sua casa. Para tanto, ela deveria se manter pura, distante dos problemas e das tentações do mundo exterior - o mundo do trabalho -, que deveria ficar sob o encargo do homem (ROCHACOUTINHO, 1994, p.29).

A separação dos espaços de atuação entre público e privado trouxe consequências que são experienciadas até os dias de hoje. Aos homens cabe o espaço público com seus desafios, poderes e produção e, do outro lado, encontra-se o espaço privado, próprio das mulheres. A elas, cabem a reprodução, o cuidado com a casa, filhos(as) e esposo. Como o papel de dona-de-casa não é compreendido como um trabalho, mas sim, como uma obrigação feminina, advinda da sua natureza de mulher, ela não goza dos direitos civis que a sociedade capitalista, em crescimento, passa a elaborar para seus trabalhadores.

Este discurso social sobre a mulher começou a se modificar no século XX. Durante as duas grandes guerras, as mulheres foram incentivadas a sair de suas casas, para atuarem no mundo produtivo, uma vez que os homens haviam partido para os campos de batalha. Para viabilizar essa saída, os meios de comunicação e a ciência mostravam as vantagens e encantos do mundo público. No entanto, no pós-guerra, ocorreu o movimento contrário. A volta dos homens para suas casas obrigou a volta das mulheres ao interior do lar. Mais uma vez, a ciência e a mídia entraram em ação, mas, desta vez, para tratar dos prejuízos para o desenvolvimento dos(as) filhos(as) que tinham mães trabalhadoras.

Criou-se todo um discurso social que culpabilizava a mãe que não se dedicasse, em tempo integral, ao seu papel natural de "cuidadora": mãe, esposa e dona-de-casa. No entanto, as mulheres já não eram as mesmas, havia "um certo mal-estar indefinido", usando as palavras de Rocha-Coutinho (1994), que deflagrou movimentos de denúncia sobre o lugar secundário o qual a mulher ocupava há anos na sociedade e sobre a diferença biológica entre os sexos ter sido transformada em diferença sociocultural. 
Eram os movimentos feministas que ganhavam força na luta pelos direitos das mulheres, num espírito de época efervescido pela luta por direitos humanos (CASTELLS, 1999; SCOTT, 1995).

A partir de então, as mulheres, progressivamente, passaram a ocupar o mundo do trabalho. Assumir o novo papel social de profissional com carreira não modificou sua identidade de mulher, apenas a ampliou. Agora, mais que mães e esposas, elas também são donas-de-casa e profissionais.

\section{Considerações Finais}

Este trabalho foi de grande relevância na vida dos envolvidos (alunos, professores, gestão escolar, servidores entre outros), uma vez que possibilitou a todos uma reflexão de como acontecem as relações de gênero na escola, pois, apesar do programa Saberes da terra trabalhar gênero como tema transversal, foi observado que, na escola, são reproduzidas as mesmas atitudes de opressão dos homens em relação às mulheres, quando estas são poupadas de certas atividades consideradas masculinas etc.

Todavia, por considerar a experiência da alternância no programa Saberes da terra, na escola Corre-Mão, município de Igarapé-Miri, como singular, adentrei na sua análise, focando particularmente as dimensões de gênero, mas para isso alguns passos foram necessários. O primeiro foi apresentar as referências da Pedagogia da Alternância com sua historicidade e sua prática; o segundo, o contato com o universo de mulheres participantes da pesquisa tanto no local de moradia quanto no espaço escolar, lugares onde se reforçam, se reconstroem ou mesmo se constroem significados de divisão do trabalho, cotidiano escolar, casamento e perspectivas para o futuro. O terceiro foi a discussão acerca das relações entre homens e mulheres como instrumento de uma teia de processos sociais que envolvem a família e a escola.

Olhando para o trajeto percorrido acima, concluímos que a Pedagogia da Alternância, fruto da luta dos movimentos sociais, se organiza em torno de uma ação educativa com o objetivo de garantir as especificidades das populações do campo. Nesse processo, buscou-se a consolidação da Pedagogia da Alternância enquanto política pública que prima pelo princípio de uma formação integral, levando em consideração as aprendizagens da família e da escola, inclusive, adotando um calendário que concilie esses tempos educacionais, facilitando a reinserção dos jovens na produção familiar. É nesse ambiente familiar e escolar que foram analisadas as relações de gênero. 
Essas relações estabelecidas na família transbordam sobre a atividade de campo da escola, as quais se utilizam de estratégias de "proteção" ao não se permitir que as alunas utilizem instrumentos de trabalho considerados como masculinos (terçado e enxada). Essa diferença entre trabalho de homem e de mulher é compartilhada pelos monitores à medida que não modificam a configuração estabelecida nessas atividades, inclusive sob o consentimento das alunas. Essa questão reflete na formação das alunas ao não participarem de todos os processos necessários a sua formação técnica.

Portanto, concluo este trabalho, com grande satisfação, ao analisar as relações de gênero no programa Saberes da terra, na escola Corre- Mão. Fica evidente que ainda hoje as mulheres têm seus direitos negados, que mesmo na escola, ainda é visível as desigualdades de gênero, onde em muitos momentos o machismo fala mais alto. Por outro lado, é notório que as mulheres têm conseguido quebrar paradigmas e garantir seus espaços, com muita audácia e dinamismo.

\section{Referências}

ARROYO, Miguel G. Apresentação. In: SOUZA, Maria Antonia de. Educação do Campo: propostas e práticas pedagógicas do MST. Petrópolis, RJ: Vozes, 2006.

ABRAMOVAY Ricardo (coord). Juventude e agricultura familiar: desafios dos novos padrões. Brasília (DF): Unesco, 1998.

CALDART, Roseli Salete. Por Uma Educação Básica do Campo - A Escola do Campo em Movimento. Vol. 03-2007.

CALDART, Roseli Salete. Elementos para Construção do Projeto Político Pedagógico da Educação do Campo. In Contribuições para a construção de um projeto de educação do campo. Brasília, DF: Articulação Nacional por uma educação do campo, 2004.

CABRAL, F.; DÍAZ, M. Relações de gênero. In: Secretaria Municipal De Educação De Belo Horizonte; Fundação Odebrecht. Cadernos afetividade e sexualidade na educação: um novo olhar. Belo Horizonte: Gráfica e Editora Rona Ltda, 1998. p. 142-150.

GIMONET, Jean-Claude. Praticar e compreender a Pedagogia da Alternância dos CEFFAS. Petrópolis, RJ: Vozes, 2007.

MOLINA, Mônica Castagna. Educação do Campo e Pesquisa: questões para reflexão. Brasília: MDA, 2006.

PARÁ. Conselho Estadual de Educação - CEE. RESOLUÇÃO Nº 001 - Dispõe sobre a regulamentação e a consolidação das normas estaduais e nacionais aplicáveis à Educação Básica no Sistema Estadual de Ensino do Pará. 2010.

PARÁ. Conselho Estadual de Educação - CEE. PARECER: No 604/2008 que regulamenta os Dias letivos para a aplicação da Pedagogia de Alternância nos Centros Familiares de Formação por Alternância (CEFFAS) no Estado do Pará. 
I Conferência Nacional Por Educação Do Campo. Luziânia, 1998 GO. Anais...

II Conferência Nacional Por Uma Educação Do Campo, Luziânia, 2004-GO. Anais...

FREIRE, Paulo. Educação como prática da liberdade. Rio de Janeiro: Paz e Terra, $28^{\text {a }}$ ed, 2005.

FREIRE. Pedagogia da Esperança: Um reencontro com a Pedagogia do Oprimido. São Paulo: Paz e Terra, 1994.

FREIRE. Pedagogia do Oprimido. Rio de Janeiro: Paz e Terra, 17 a ed,. 1987.

PEDRO, Joana Maria, Traduzindo o debate: o uso da categoria gênero na pesquisa histórica; história, São Paulo, v.24, N.1, P.77-98, 2005.

CARNEIRO, Roseli. Por uma Educação do Campo: traços de uma identidade em construção. In: ARROYO, Miguel, CALDART, Roseli e MOLINA, Mônica C. (organizadores) Por Uma Educação do Campo. Petrópolis, RJ: Vozes, 2004.

SCOTT, J. Gênero: uma categoria útil de análise histórica. Educação e Realidade, 1995.

ROCHA-COUTINHO M.L. Tecendo por trás dos panos. A mulher brasileira nas relações familiares. Rio de Janeiro: Rocco, 1994.

VERGUTZ, Cristina Luisa Bencke; CAVALCANTE, Ludmila Oliveira Holanda. As aprendizagens na pedagogia da alternância e na educação do campo. Revista Reflexão e Ação, Santa Cruz do Sul, v.22, n.2, p.371-39. 2014.

FARIA, Nalu; NOBRE, Miriam. Subsídio para uma discussão de gênero. mimeo; In: SILVA, Carla. A desigualdade imposta pelos papéis de homem e mulher: uma possibilidade de construção da igualdade de gênero.

MIRANDA, T. L.; SCHIMANSKI, E. Relações de gênero: algumas considerações conceituais. In: FERREIRA, AJ., org. Relações étnico-raciais, de gênero e sexualidade: perspectivas contemporâneas [online]. Ponta Grossa: Editora UEPG, 2014, pp. 66-91. ISBN 978-85-7798-210-3. Available from SciELO Books <http://books.scielo.org>. 